\title{
3 Research Square

\section{Early-life Psychological Stress Leads to Impaired Spatial Learning and Memory and Alters Hippocampal Proteome in Adult Rats}

\section{Lin Han}

Xi'an Jiaotong university https://orcid.org/0000-0002-9597-9535

\section{Xiaofan Xiong}

Xi'an Jiaotong University

\section{Meiyang Fan}

Xi'an Jiaotong University

\section{Lingyu Zhang}

Xi'an Jiaotong University

Liying Liu

Xi'an Jiaotong University

Chen Guo

Xi'an Jiaotong University

Shanfeng Gao

Xi'an Jiaotong University

Xiaofei Wang

Xi'an Jiaotong University

Lingyu Zhao

Xi'an Jiaotong University

Xuan Xiao

Xi'an Jiaotong University

Chen Huang

Xi'an Jiaotong University

Juan Yang ( $\square$ yangjuan0112@mail.xjtu.edu.cn )

Xi'an Jiaotong University

\section{Research}

Keywords: Early-life psychological effects, Learning and memory, Hippocampus, 2DE, Proteomics

Posted Date: November 10th, 2021

DOI: https://doi.org/10.21203/rs.3.rs-1007353/v1 
License: (c) (i) This work is licensed under a Creative Commons Attribution 4.0 International License. Read Full License 


\section{Abstract}

Early-life psychological stress (ELPS) can cause anxiety, pessimism, and a decrease of cognitive ability in adult individuals. In this study, a psychological stress model (a terrified sound stress) was applied to newborn Sprague-Dawley rats for 21 days. And then, we separately evaluated the impact of ELPS on their spatial learning and memory abilities and hippocampal proteome from early-stage to the adult-stage. The Morris Water Maze (MWM) test was employed to evaluate their spatial learning and memory abilities after ELPS till to the adult-stage. Two-dimensional gel electrophoresis (2DE) as well as matrix-assisted laser desorption/ionization time-of-flight mass spectrometry (MALDI-TOF-MS) were used to uncover the protein expression profile of the hippocampus from both ELPS-young and ELPS-adult as well as their control groups. We found that the rats had a dysfunction of spatial learning and memory after the ELPS till to the adult-stage. The proteomic analysis revealed that 51 proteins were significant differentially expression, and 25 of them were down-regulated, while the other 26 proteins were up-regulated in the hippocampus of the ELPS-young rats compared with the controls. In the ELPS-adult rats, there were 56 significant differentially expression proteins, and 42 of them were down-regulated, the other 14 proteins were up-regulated in the hippocampus compared with their controls. Thirteen of the most significant differentially expressed proteins in ELPS-adult hippocampus were identified as SPTAN1, MYH4, HSPA8, HS90A, DYN1, DLDH, ARP3, GLNA, SAHH, HBB1, ACLY, TBB2A and GBB1, that demonstrated the greatest stress-induced changes. Furthermore, western blotting analyses consistently showed that the reduced expression of SPTAN1 and MYH4 whereas the expression of HSPA8 was up-regulated in the hippocampus after ELPS till to the adult-stage. The current study showed the impaired spatial learning and memory and changed hippocampal gene expressions induced by ELPS from early-stage to adultstage in rats. This study shows that ELPS plays an important role in behavioral cognition and hippocampal protein expression in adult rats.

\section{Introduction}

The juvenile brain undergoes a period of growth and development, and is more sensitive to external stimuli than adult brains. Early life stress (ELS) affects hippocampal neurogenesis, increases depressivelike behavior, and causes mild metabolic imbalance in adulthood[1]. Roberto Ruiz et al. found that maternal separation caused more severe depressive-like behavior in middle-aged (10-months-old) adults than in young (4-months-old) animals[2]. Felipe V. Gomes et al. found that all adolescent stressors (restraint stress [RS], foot-shock [FS], or the combination of FS and RS) impaired weight gain and induced anxiety-like responses,FS and FS + RS also disrupted cognitive function in adult rats[3].

The hippocampal formation is rich in GC receptors and is highly sensitive to developmental stress[4]. The first 2 postnatal weeks comprise a crucial period in hippocampal maturation as this is when the hippocampal commissural/associational (C/A) pathways establish their synaptic connections on CA3 pyramidal cell dendrites[5]. Disruption of this process can only be partially restored beyond the third postnatal week[6], making that stress experienced during this period can profoundly affect hippocampal 
structure and function. There is ample evidence from human and animal studies that early life experiences have profound effects on hippocampal mediated memory function in adulthood[7-10].

Psychological stress refers to the process of psychological and physiological changes caused by the perception and assessment of the threat of stressors when the body is stimulated by various internal and external environmental factors. Long-term intense psychological stress can severely affect the human health, such as learning and memory impairments, dementia, accelerating aging of normal aging processes, causing depression and low immunity[11-15]. Interestingly, recent studies have shown that psychological stress in early life such as maternal separation stress, caused learning and memory deficits, emotional anxiety, negative emotions and reduced cognitive abilities in adulthood[16, 17].

Importantly, does our established psychological stress (scream sound stress) on newborn rats affect their learning and memory ability in adult? And then, we established the early-life psychological stress on newborn rats for 21 days and concluded decreased learning and memory abilities of rats in adult. In addition, the current study on the effects of psychological stress on learning and memory is mainly focused on the behavior of stressed animals, changes in hippocampal pyramidal cell morphology, changes in receptors and genes related to the hippocampus, and related protein expression changes[1821]. The formation and stabilization of memory is an ever-renewing process, in which protein synthesis is required at each stage, and each process involves the reticulation of genes[22]. At present, research on the effects of early psychological stress on gene expression patterns of stressed individuals using proteomics is rare. Therefore, it is necessary to determine the effects, based on proteomics, of early life psychological stress on spatial learning and memory during adulthood to reveal complex signal pathways.

\section{Materials And Methods}

\subsection{Animals and experimental protocol}

21 female Sprague-Dawley rats aged about 80 days and weighing between 250-300g, and 7 male Sprague-Dawley rats aged about 90 days and weighing between 300-350g were obtained from the Laboratory Animal Center, Xi'an Jiaotong University (Medical Experimental Animal Centre of Shaanxi Province, China). Female rats were randomly divided into seven cages, and three female rats and one male rat were housed in one cage for breeding. Pregnant female rats $(n=20)$ were separately raised in a single cage until gave birth to pups. There were totally 120 male pups and 4 male pups per cage at least. Pups with their mothers were randomly divided into two group: ELPS group ( $\mathrm{n}=10$ cages) and Control group ( $n=10$ cages). In current study, we exposed pups with their mothers from postnatal day 1 (P1) - P21 to the terrified sound to induce early-life psychological stress (ELPS). On postnatal day 22 (P22), pups weaned and 2 newly weaned rat per litter from ELPS or Control group were used as Control-young group $(n=20)$ and ELPS-young group $(n=20)$. These rats were tested for learning and memory ability $(n=14)$ and were prepared for hippocampus isolation $(n=6)$ per group. Meanwhile, another two newly weaned rat per litter from ELPS or Control group were used as Control-adult group $(n=20)$ and ELPS-adult group $(n=20)$, 
and they were raised without additional intervention until 80 days and then underwent a Morris water maze test $(n=14)$ and hippocampus isolation $(n=6)$ per group. The hippocampal tissues of these rats were prepared for 2DE/MS ( $n=3 /$ group) and Western blotting ( $n=3 /$ group) (Fig. 1B).

All rats were housed in a temperature-controlled $\left(25 \pm 2^{\circ} \mathrm{C}\right)$ animal transit room with a $12 \mathrm{~h}$ light/dark cycle throughout the study. Rat food pellets and clean tap water were provided ad libitum. All experiments were performed in accordance with relevant guidelines and regulations and all animal procedures were approved by the Animal Ethics Committee of Xi'an Jiaotong University (Permit Number: XJTULAC2017705).

\subsection{Early-life psychological stress (ELPS)}

According to the terrified sound psychological stress model established in our previous research[23], six male rats were exposed to a $40-60 \mathrm{~V}$ electric foot shock, and their terrified sound in response to the electric shock were simultaneously recorded in a professional recording room (Fig. 1A). In current study, we exposed pups from postnatal day (PND) 1 (P1) - P21 to the terrified sound to induce early-life psychological stress (ELPS). The terrified sound was played for $3 \mathrm{~h}$ in the morning and $3 \mathrm{~h}$ in the afternoon for 21 consecutive days (Fig. 1B). The loudspeaker broadcasting the terrified sound was located $50 \mathrm{~cm}$ above the animal cages, and the sound intensity was $45-60 \mathrm{~dB}$. Control group was kept in a room with a 40-45dB ambient noise level. During ELPS exposure, all pups were housed with their mother in a temperature-controlled $\left(25 \pm 2^{\circ} \mathrm{C}\right)$ animal transit room with a $12 \mathrm{~h}$ light/dark cycle throughout the study, food pellets and clean tap water were provided ad libitum.

\subsection{Morris water maze test}

The circular pool for the Morris water maze test had a diameter of $90 \mathrm{~cm}$ and a height of $50 \mathrm{~cm}$, and was divided into four quadrants (I, II, III, and IV) at four equidistant points named east (E), south (S), west (W), and north $(\mathrm{N})$ on the pool wall. A circular platform with a diameter of $8 \mathrm{~cm}$, a height of $31 \mathrm{~cm}$, and below the water level by about $2 \mathrm{~cm}$, was placed $30 \mathrm{~cm}$ away from the wall of the IV quadrant. Before the experiments, the circular pool was filled with water to a depth of $30 \mathrm{~cm}$. During the experiments, the water temperature was set at $23 \pm 0.5^{\circ} \mathrm{C}$.

During cognitive spatial ability testing, each animal underwent four trials daily for 5 consecutive days. Each trial was started from a different location and lasted for 120s, with the rats facing the wall of the pool when placed into the water. When the rats located the platform, they were allowed to stay on the platform for $15 \mathrm{~s}$ before the next trial. If the rats failed to locate the platform within 120 s, they were guided to the platform and allowed to stay there for $15 \mathrm{~s}$. The escaping latency and the travel orbit of each rat were recorded by the tracking system. On the sixth day, the rats were given 120 s to explore the pool with the platform removed. All tests were recorded by Smart 3.0 video-tracking software (RWD, Shen Zhen, China).

\subsection{Sample preparation}


The rats $(n=6)$ per group were separately euthanized by chloral hydrate $(400 \mathrm{mg} / \mathrm{kg})$ and their hippocampus were stripped from the brains on ice, quickly frozen with liquid nitrogen, and stored at

$-80^{\circ} \mathrm{C}$. To test protein expression profile of the hippocampus by $2 \mathrm{DE}$, the same mass of hippocampal tissue $(n=3)$ per group was crushed using a mortar and pestle and liquid nitrogen, and each sample in the $2.0 \mathrm{~mL}$ centrifuge tube was mixed with lysis buffer to obtain a $150 \mathrm{mg} / \mathrm{mL}$ concentration. The lysis buffer contained 40mM Tris-HCl (pH8.5), 8M urea, 4\% CHAPS, $0.5 \%$ ampholytes, $1 \mathrm{mM} \mathrm{PMSF}, 2 \mathrm{mM}$ EDTA, and $40 \mathrm{mM}$ DTT. Each lysate was sonicated on ice for $5 \mathrm{~min}$ (sonicated $2 \mathrm{~s}$, interval $3 \mathrm{~s}$ ), and then centrifuged at $14,000 \times \mathrm{g}$ for $30 \mathrm{~min}$ at $4^{\circ} \mathrm{C}$. The supernatant of three samples per group were mixed and used for protein purification. The purification and quantification of proteins was determined using the 2-D Quant Kit (GE Healthcare, Sunnyvale, CA, USA).

\subsection{Isoelectric focusing (IEF) and polyacrylamide gel electrophoresis (PAGE)}

The IEF was performed using an EttanIPGphor III IEF system (GE Healthcare) at $20^{\circ} \mathrm{C}$ with a current limit of $50 \mu \mathrm{A}$ per strip. The hippocampal supernatants containing $1 \mathrm{mg}$ of total protein were diluted to $350 \mu \mathrm{L}$ with heavy loading solution containing $8 \mathrm{~mol} / \mathrm{L}$ urea, $2 \%$ CHAPS, $18 \mathrm{mmol} / \mathrm{L} \mathrm{DTT}, 0.5 \%$ IPG buffer and a trace amount of bromophenol blue dye. The $18 \mathrm{~cm}$ IPG strips had a nonlinear pH gradient of 3 to 10 and the sample volume for each strip was $350 \mu \mathrm{L}$. The IEF electrophoresis procedure was performed in the following consecutive steps: $30 \mathrm{~V}$ for $12 \mathrm{~h} ; 200 \mathrm{~V}$ for $1 \mathrm{~h} ; 500 \mathrm{~V}$ for $1 \mathrm{~h} ; 1000 \mathrm{~V}$ for $1 \mathrm{~h}$; a 1000 to $8000 \mathrm{~V}$ gradient for $1 \mathrm{~h}$; and $8000 \mathrm{~V}$ for $2 \mathrm{~h}$. After the completion of IEF, the strips were placed in equilibration buffer containing $50 \mathrm{mM}$ Tris- $\mathrm{HCl}$, pH8.8, $6 \mathrm{M}$ urea, $30 \%(\mathrm{v} / \mathrm{v})$ glycerol, $2 \%(\mathrm{w} / \mathrm{v})$ sodium dodecyl sulfate (SDS), $1 \%(\mathrm{w} / \mathrm{v}$ ) DTT, and a trace amount of bromophenol blue dye, for $10 \mathrm{~min}$, followed by another $10 \mathrm{~min}$ incubation in equilibration buffer containing $4 \%(\mathrm{w} / \mathrm{v})$ iodoacetamide instead of DTT. The second electrophoresis step was performed with $12 \%$ acrylamide gel at $20^{\circ} \mathrm{C}$ for $4 \mathrm{~h}$ using an Ettan-Dalton electrophoresis unit at a power setting of $20 \mathrm{~W}$.

After electrophoresis, the polyacrylamide gels were fixed for $30 \mathrm{~min}$ in fixing solution containing $10 \%(\mathrm{v} / \mathrm{v})$ acetic acid and $30 \%(\mathrm{v} / \mathrm{v})$ ethanol, and then were stained for $90 \mathrm{~min}$ in a solution containing $5 \%(\mathrm{v} / \mathrm{v})$ methanol, $42.5 \%$ ethanol, $10 \%$ acetic acid, $30 \%$ ethanol, $0.2 \%$ (w/v) Coomassie Brilliant Blue (CBB) G250 dye, and $0.05 \%$ CBB R250 dye. Next, the polyacrylamide gels were destained for $60 \mathrm{~min}$ in fixing solution, followed by additional destaining in $7 \%$ acetic acid until the gel background was clear. The gels of the stress group and the control group were scanned and analyzed with Image Master 2D Platinum, version 6.0, software (GE Healthcare). The different protein bands or spots were manually excised from the stained polyacrylamide gels for further identification by MALDI-TOF-MS.

\subsection{Protein identification by MALDI-TOF-MS}

Peptide mass fingerprinting was performed on a Bruker Daltonics 4700 Proteomics Analyzer MALDI-TOFTOF mass spectrometer (Bruker, Ettlingen, Germany). After image analyses, we conducted in-gel enzyme digestion. Firstly, we cut the spot from the gel with a $1.5 \mathrm{~mm}^{3}$ pencil and placed it in a $1.5 \mathrm{~mL}$ Eppendorf 
tube washing twice with $500 \mu \mathrm{L}$ double-distilled water for 10 min each. Then, a solution containing $50 \%$ acetonitrile and $25 \mathrm{mmol} / \mathrm{L} \mathrm{NH}_{4} \mathrm{HCO}_{3}$ was used for decolorization. The decolorized rubber block was dried in a vacuum centrifuge dryer for about $20 \mathrm{~min}$ to reduce the dehydration volume of the rubber block to an approximate ball and that was dissolved with $3-7 \mu \mathrm{L}$ of $0.01 \mu \mathrm{g} / \mu \mathrm{L}$ trypsin solution containing $25 \mathrm{mmol} / \mathrm{L}$ $\mathrm{NH}_{4} \mathrm{HCO}_{3}$ solution at $4^{\circ} \mathrm{C}$ for $15 \mathrm{~min}$. When the enzyme solution was completely absorbed by the colloidal particles, we added $25 \mathrm{mM} \mathrm{NH}_{4} \mathrm{HCO}_{3}$ to the total volume of $10-15 \mu \mathrm{L}$ overnight at $37^{\circ} \mathrm{C}$. Finally, we added $0.1 \%$ TFA or $50 \% \mathrm{CH}_{3} \mathrm{CN}+0.1 \%$ TFA to terminate the reaction, oscillated and mixed well, and centrifuged to collect the hydrolysate. $1 \mu \mathrm{L}$ of the sample solution obtained from the in-gel digestion was mixed with an equal volume of a saturated matrix HCCA (a-cyano-4-hydroxycinnamic acid) solution, and the mixture was spotted and the target was spotted. After drying at room temperature, the target plate was put into a mass spectrometer in a linear mode for analysis. Samples were detected after calibration using a standard and Flex Control 2.0 software to obtain the protein peptide spectra with different cytoplasmic ratios ( $\mathrm{m} / \mathrm{z}$ ). The protein peptide spectra were analyzed using Flex Analysis 3.0 software.

\subsection{Western blotting validation of proteins}

Western blotting was performed using standard methods. Briefly, the rat hippocampi ( $n=3 /$ group) were lysed on ice in RIPA Buffer with Phostop (Roche, Berlin, Germany), protease inhibitors (Roche), and PMSF (Sigma-Aldrich, St. Louis, MO, USA). The protein samples concentration was measured by using a BCA kit (Pierce, Waltham, MA, USA). A mixture protein of three samples per group were separated by electrophoresis in an SDS-PAGE gel and electroblotted onto a PVDF membrane (Millipore, Temecula, CA, USA). Membranes were probed with specific primary antibodies and peroxidase-conjugated secondary antibodies (Jackson ImmunoResearch, West Grove, PA, USA). Then, chemiluminescent signals were visualized for bands using the tagged HRP substrate (Millipore, Hayward, CA, USA). The following antibodies were used: anti-SPTAN1 (Abcam; ab133342); anti-MYH4 (Proteintech; 20140-1-AP); antiHSPA8 (Proteintech; 66442-1-Ig); anti-GFAP (Abcam; ab33922) and anti- $\beta$-actin (Abways; AB0035).

\subsection{Statistical analysis}

Student's t-test was used to determine the differences between two groups. MWM data was analyzed by two-way repeated measures ANOVA with ELPS as one factor and training days as the second factor. All data was analyzed by IBM SPSS Statistics 22 and presented as the mean \pm SEM. All figures were presented using GraphPad Prism 9.0. A p-value of less than .05 was considered statistically significant $(*)$, less than .01 as extremely significant $\left({ }^{\star *}\right)$ and less than .001 as extremely significant $(* \star \star)$.

\section{Results}

\subsection{Effects of ELPS on spatial learning and memory}

On the second day after the completion of ELPS for 21 days, the Morris Water Maze test was used to investigate changes in spatial learning and memory. As shown in Fig. 2A and E, the escape latency of the Control-young and ELPS-young groups gradually decreased; ELPS-young rats spent more time finding the 
target but was no significant difference between them. In the probe trial with the platform removed, the number of times of ELPS-young rats crossing the platform position was fewer than the control groups (Fig. 2B); the ELPS-young rats spent less time (Fig. 2C), had less distance (Fig. 2D and J) in the target quadrant. These results indicated that ELPS might result in a dysfunction of spatial learning and memory in young rats and we suspected ELPS may have long-term effects.

To investigate whether ELPS had a lasting effect of spatial learning and memory on adult rats, we performed the Morris Water Maze test. In the spatial learning analyses, the ELPS-adult rats significantly spent more time finding the platform (repeated measures ANOVA, F=4.949, $\mathrm{P}=0.035$; Fig. $2 \mathrm{~F}$ and $\mathrm{J}$ ). In the spatial memory analysis, with the platform removed, ELPS-adult rats crossed the platform position less frequently than the control groups ( ${ }^{*} P<0.05$; Fig. $\left.2 G\right)$; the ELPS-adult rats spent less time $\left({ }^{\star \star *} P<0.001\right.$; Fig. $2 \mathrm{H}$ ), had less distance ( ${ }^{\star \star \star} \mathrm{P}<0.001$; Fig. $2 \mathrm{I}$ and $\mathrm{J}$ ) in the target quadrant. Overall, our results showed a continuous reduction learning and memory ability in ELPS rats compared with the control rats from early to adult.

\subsection{Effects of ELPS on hippocampal proteomics profiling}

The effects of ELPS on the expression of proteins in the rat hippocampus were constructed by highresolution 2DE maps. There were $422 \pm 17$ and $382 \pm 39$ spots on the Control-young and ELPS-young rat $2 \mathrm{DE}$ gels, respectively. The statistical analysis of the $2 \mathrm{DE}$ data revealed that the volumes of 51 protein spots were significantly different between the ELPS-young and Control-young groups (fold change>2; $\mathrm{P}<0.01)$. In the ELPS-young rats, the expression of 25 proteins was down-regulated in the hippocampus, and that of 26 proteins was up-regulated. In the meantime, there were $298 \pm 4$ and $299 \pm 1$ spots on the Control-adult and ELPS-adult rat 2DE gels, respectively. The statistical analysis of the 2DE data revealed that the volumes of 56 protein spots were significantly different between the ELPS-adult and Controladult groups (fold change $>2 ; \mathrm{P}<0.01$ ). In the ELPS-adult rats, the expression of 42 proteins was downregulated in the hippocampus, and that of 14 proteins was up-regulated (Fig. 3A). Thirteen (spot number: 1-13) of the most significant differentially expressed proteins in ELPS-adult and Control-adult rats were further identified, which the difference in the relative levels of expression was greatest, the expression of 9 proteins (spot number: 1, 2, 4, 5, 6, 7, 8, 9\&10) were down-regulated in the ELPS-adult rats and 2 (spot number: $2 \& 8$ ) of them were continue to express down from early to adult; 4 protein spots (spot number: 3 , $11,12 \& 13$ ) were up-regulated and 1 (spot number: 3 ) of them were continue to express up from early to adult. (Fig. 3B and C).

\subsection{Identification and validation of differentially expressed proteins}

The 13 protein spots were further identified using MALDI-TOF-MS, and were identified as spectrin alpha chain, non-erythrocyte 1 (SPTAN1), myosin-4 (MYH4), heat shock cognate 71 kDa protein (HSPA8), heat shock protein HSP 90-alpha (HS90A), dynamin-1 (DYN1), dihydrolipoyl dehydrogenase mitochondrial (DLDH), actin-related protein 3 (ARP3), glutamine synthetase (GLNA), adenosyl homocysteinase (SAHH), hemoglobin subunit beta-1 (HBB1), ATP-citrate synthase (ACLY), tubulin beta-2A chain (TBB2A), and 
guanine nucleotide-binding protein $\mathrm{G}(\mathrm{I}) / \mathrm{G}(\mathrm{S}) / \mathrm{G}(\mathrm{T})$ subunit beta-1 (GBB1). The details of the 13 identified protein spots are listed in Table1.

Immunoblotting was used to confirm the relative levels of differential expression and the identities of the proteins that were previously identified in the 2DE, MALDI-TOF-MS, and PMF analyses including SPTAN1 (No. 1), MYH4 (No. 2), and HSPA8 (No. 3) (Fig. 4A). The western blotting analysis showed that the amounts of HSPA8 were greater in the hippocampus both of the ELPS-young vs. Control-young and ELPS-adult vs. Control-adult rats, whereas the amounts of SPTAN1 and MYH4 were less in the hippocampus of the ELPS-adult rats (Fig. 4B). These results are consistent with those of the 2DE analysis. Moreover, the amounts of GFAP were less in the hippocampus both of the ELPS-young vs. Control-young and ELPS-adult vs. Control-adult rats.

\subsection{Gene ontology (GO) analysis of differentially expressed proteins}

In order to obtain further information of the 13 differentially expressed proteins, the UniProt (https://www.uniprot.org/) and QuickGO (https://www.ebi.ac.uk/QuickGO) online databases were used to classify the molecular functions, biological processes, and cellular components. For the GO classification for biological processes, most of the proteins were involved in cellular processes (18\%) (Fig. 5A). Considering the $\mathrm{GO}$ classification for Molecular Function, most of the differentially abundant proteins were divided in three classes, including binding and catalytic activity, accounting for up to $88 \%$ of the proteins (Fig. 5B). Investigating the GO classification for Cellular Component, most of the 13 differential proteins participated in Cell Part (22\%) (Fig. 5C). Those findings suggested that modifications in ELPS impacted primarily on the cellular functions of the rat hippocampus.

\subsection{Figures and Tables}

(A) Rats were exposed to a 40-60V electric foot shock, and their terrified sound in response to the electric shock were simultaneously recorded in a professional recording room. We exposed other rats to the recorded terrified vocalization to induce psychological stress. (B) With their mothers, pups on postnatal day 1 (P1) were exposed to the terrified sound to induce early-life psychological stress (ELPS). At P22, after ELPS exposure, Control-young group $(n=14)$ and ELPS-young group $(n=14)$ were tested for learning and memory ability by the Morris water maze test. To explore whether ELPS mediated spatial learning and memory ability in adult rats, Control-adult group $(n=14)$ and ELPS-adult group $(n=14)$ were raised without additional treatment until 80 days and then underwent a Morris water maze test. The hippocampal tissues of rats $(n=6)$ per group were prepared for 2DE, MS and Western blotting.

(A-D) The ELPS-young group required more time to find escape platform; had fewer number of times crossing the platform position; spent less time and had less distance in the target quadrant, but there was no significant difference between the two groups. (F-I) The ELPS-adult group required more time to find escape platform; had less times crossing the platform position; spent less time and had less distance in the target quadrant, and there was significant difference between the two groups. $(E, J)$ Representative 
swimming tracks of all groups in the Morris Water Maze test for days 1-5 of training and day 6 of the probe trial. $N=14$ per group. $\left({ }^{*} P<0.05,{ }^{\star} \times P<0.01,{ }^{*} * \mathrm{P}<0.001\right.$; NS: not significant).

Figure 3. Different protein spots expression in 2DE gels.

(A) Representative 2DE map of rat hippocampus proteome from the Control-young group, ELPS-young group, Control-adult group and ELPS-adult group. The expression quantity of 13 spots corresponding to the most significant differentially expressed proteins between the Control-young group and ELPS-young group (B); Control-adult group and ELPS-adult group (C). The figures used the independent Student's t-test of statistical methods. ${ }^{*} \mathrm{P}<0.05,{ }^{\star *} \mathrm{P}<0.01,{ }^{\star \star *} \mathrm{P}<0.001$.

Figure 4. Identification and validation of differentially expressed proteins.

(A) Differentially concentrated spots $(1,2,3)$ identified as SPTAN1, MYH4, HSPA8 by MALDI-TOF-MS are marked with red arrows in the Control-young group, ELPS-young group, Control-adult group and ELPSadult group. (B) Western blotting analysis of SPTAN1, MYH4, HSPA8 and GFAP in the hippocampus of Control-young group, ELPS-young group, Control-adult group and ELPS-adult group.

Proteins were classified using UnitProtKB and GO database according to their (A) biological processes, (B) molecular functions and (C) cellular components. 
Table 1

Protein spots differentially expressed in the control vs the ELPS rats identified using peptide mass fingerprinting and Mascot search analyses of the MALDI-TOF-MS data.

\begin{tabular}{|c|c|c|c|c|c|c|c|}
\hline \multirow[t]{2}{*}{$\begin{array}{l}\text { Spot } \\
\text { no. }\end{array}$} & \multirow[t]{2}{*}{$\begin{array}{l}\text { Accession } \\
\text { number }\end{array}$} & \multirow[t]{2}{*}{ Protein name } & \multirow{2}{*}{$\begin{array}{l}\text { Molecular } \\
\text { mass } \\
(\mathrm{MS})^{\mathrm{a}}\end{array}$} & \multirow{2}{*}{$\begin{array}{l}\text { Sequence } \\
\text { Coveragea } \\
(\%)^{a}\end{array}$} & \multirow[t]{2}{*}{$\begin{array}{l}\text { Mascot } \\
\text { score }^{a}\end{array}$} & \multicolumn{2}{|c|}{$\begin{array}{l}\text { Fold } \\
\text { change }^{b}\end{array}$} \\
\hline & & & & & & A/B & C/D \\
\hline 1 & SPTN1_RAT & $\begin{array}{l}\text { Spectrin alpha chain, } \\
\text { non-erythrocytic } 1\end{array}$ & 284462 & $58(56)$ & 5655 & $\#$ & 0.35 \\
\hline 2 & MYH4_RAT & Myosin-4 & 222741 & $25(18)$ & 668 & 0.54 & 0.32 \\
\hline 3 & HSP7C_RAT & $\begin{array}{l}\text { Heat shock cognate } 71 \\
\text { kDa protein }\end{array}$ & 70827 & $21(21)$ & 2557 & 1.60 & 2.15 \\
\hline 4 & HS90A_RAT & $\begin{array}{l}\text { Heat shock protein } \\
\text { HSP 90-alpha }\end{array}$ & 84762 & $24(24)$ & 4171 & 0.95 & 0.31 \\
\hline 5 & DYN1_RAT & Dynamin-1 & 97234 & $15(13)$ & 722 & 0.94 & 0.42 \\
\hline 6 & DLDH_RAT & $\begin{array}{l}\text { Dihydrolipoyl } \\
\text { dehydrogenase, } \\
\text { mitochondrial }\end{array}$ & 54004 & $6(5)$ & 327 & 0.69 & 0.35 \\
\hline 7 & ARP3_RAT & Actin-related protein 3 & 47327 & $12(9)$ & 423 & 0.99 & 0.49 \\
\hline 8 & GLNA_RAT & Glutamine synthetase & 42240 & $12(12)$ & 1738 & 0.75 & 0.23 \\
\hline 9 & SAHH_RAT & $\begin{array}{l}\text { Adenosyl } \\
\text { homocysteinase }\end{array}$ & 47507 & $13(11)$ & 571 & 0.77 & 0.18 \\
\hline 10 & HBB1_RAT & $\begin{array}{l}\text { Hemoglobin subunit } \\
\text { beta-1 }\end{array}$ & 15969 & $11(10)$ & 5282 & 1.40 & 0.38 \\
\hline 11 & ACLY_RAT & ATP-citrate synthase & 12055 & $8(6)$ & 125 & 1.59 & 2.70 \\
\hline 12 & TBB2A_RAT & Tubulin beta-2A chain & 49875 & $12(11)$ & 1386 & 2.36 & 3.03 \\
\hline 13 & GBB1_RAT & $\begin{array}{l}\text { Guanine nucleotide- } \\
\text { binding protein } \\
G(I) / G(S) / G(T) \text { subunit } \\
\text { beta- } 1\end{array}$ & 37353 & $7(6)$ & 540 & 1.00 & 2.36 \\
\hline \multicolumn{8}{|c|}{$\begin{array}{l}\text { a Identities of the protein spots were matched to the position of the spots in the } 2 \mathrm{D} \text { gels (values given } \\
\text { in parenthesis). }\end{array}$} \\
\hline \multicolumn{8}{|c|}{$\begin{array}{l}\mathrm{b} \text { The fold expression between isolation and control group from early to the adulthood. }{ }^{*} \mathrm{p} \text { value }<0.05 \text {. } \\
\text { \# No data detected. }\end{array}$} \\
\hline A: ELF & young; B: Co & ol-young; C: ELPS-adult; & Control-a & & & & \\
\hline
\end{tabular}

\section{Discussion}


The effects of stress in early-life also appear to produce changes to hippocampal neurogenesis that last into adulthood in rats[24]. Previous studies suggested that acute and chronic stress exposure during adolescence led to long-term changes in performance in hippocampal dependent cognitive behavioral tasks[25, 26]. In this study, a terrified-sound stress has been used to determine the effects of psychological stress on hippocampal physiology and spatial learning and memory in early-life of rats. Moreover, we firstly used a proteomic approach to investigate the relationship between changes in spatial learning and memory and the protein expression profile of the hippocampus caused by early-life psychological stress (ELPS). Our results suggested that ELPS impaired spatial learning and memory in rats' early life till to adult, and that changes in protein expression in the hippocampus coincide with the effects on spatial learning and memory.

The hippocampus, a cyto-architecturally distinct structure folded into the cerebral cortex, plays an important role in stress response, learning and memory[27]. M. Fountoulakis et al. reported a detailed twodimensional database for the rat hippocampus proteome, and the identification of the products of 148 different genes, which were in the majority enzymes, structural proteins, and heat shock proteins groups, including GFAP and HSPA8[28].We used 2DE- and MS-based proteomic analyses to examine differential protein expression in the hippocampus of ELPS rats. Our statistical analysis showed 13 significantly different protein spots in ELPS-adult and Control-adult rats (fold change $>2 ; \mathrm{P}<0.01$ ). The 13 protein spots were further identified using MALDI-TOF-MS as SPTAN1, MYH4, HSPA8, HS90A, DYN1, DLDH, ARP3, GLNA, SAHH, HBB1, ACLY, TBB2A, and GBB1. In the ELPS-adult group, the expression of 9 proteins (SPTAN1, MYH4, HS90A, DYN1, DLDH, ARP3, GLNA, SAHH and HBB1) were down-regulated and 2 (MYH4 \& GLNA) of them were continue to express down from early to adult. Four proteins (HSPA8, ACLY, TBB2A and GBB1) were up-regulated and 1 (HSPA8) of them was continue to express up from early to adult (Table 1, Fig. 3).

The SPTAN1 gene encodes the cytoskeletal protein all spectrin that playing a critical role in brain development and epileptic encephalopathy[29]. Mice lacking all spectrin are embryonic lethal due to nervous system malformations[30]. Yu Wang et al. showed that dendritic number and length were significantly decreased in Sptan1 CRISPR deletion-transfected hippocampal neurons as compared with control neurons. Loss of all spectrin also led to defects in axon development. Therefore, breakdown of SPTAN1 may be a common molecular pathology in neurodegenerative diseases and injuries[31, 32]. These findings are consistent with our observations that the ELPS-induced reduction in SPTAN1 expression in the rat hippocampus coincided with increased escape latency and reduced the crossing numbers of platform, time and distance in the target quadrant, suggesting that the ELPS-mediated reduction in SPTAN1 expression is related to reduced spatial learning and memory in rats' early life till to adult.

The function of MYH4 involves muscle contraction. Toshinori Yoshihara et. al observed that Myh4 mRNA expression was related to age process. As type Ilb MHC protein, Myh4 mRNA expression declined in rats at 12 and 24 months of age, suggesting a progressive degeneration and atrophy of skeletal muscles 
during the aging process[33]. Interesting, our research firstly showed that the ELPS reduced the expression of MYH4 in rats at adulthood. Above all, MYH4 is important to development process in rats.

Heat shock proteins (HSPs) were initially described as a large family of proteins mediating the cellular response to environmental stress such as elevated temperature, heavy metals or anoxia. Heat shock cognate $71 \mathrm{kDa}$ protein (HSPA8), also known as Hsc70 or Hsp73, is a molecular chaperone implicated in a wide variety of cellular processes such as protection from stress and Hspa8 was found at high levels in multiple stress-related brain regions and the hypothalamic-pituitary-adrenal (HPA) stress-axis[34, 35]. Hspa8 induces other members of the family, such as HSF-1, the transcription factor for Hsp70[36]. Previous study indicated that psychophysiological stress induced heat shock cognate protein $70 \mathrm{mRNA}$ expression in the hippocampus of rats[37]. Consistent, our western blotting analysis showed that the amounts of HSPA8 were greater in the hippocampus both of the ELPS-young vs. Control-young and ELPS-adult vs. Control-adult rats. Thus, Hspa8 is potentially the initiator of the stress response.

GFAP, a class-III intermediate filament, is a cell-specific marker that, during the development of the central nervous system, distinguishes astrocytes from other glial cells[38]. Indeed, a wealth of investigations now shows that astrocytes regulate processes of handling information and memory formation[39]. The mutation of GFAP in a mouse model of Alexander's disease showed deficiencies in spatial memory as assessed in the Morris Water Maze[40]. In an animal study, western blot analyses showed that chronic stress down-regulated GFAP in adult male rats[41]. Our results showed a reduction of GFAP expression by ELPS in the rat immature hippocampus that lasted into adulthood, which might be one of reasons for impaired learning and memory.

In conclusion, we found that early-life psychological stress (ELPS) reduced spatial learning and memory of rats from early to adult, and that the stress-induced impairment in spatial learning and memory coincides with changes in the expression profile of cells in the hippocampus. Our GO analysis showed that the ELPS-induced modifications of differently expressed proteins impacted primarily on the cellular functions of the rat hippocampus. Our study provided a theoretical foundation for investigating the effects of early-life stress on individuals manifested during adulthood. More importantly, the formation and stabilization of memory is an ever-renewing process, which protein synthesis is required at each stage. Some differentially expressed proteins we found are critical for dendritic and axonal development and synaptogenesis, and associated with nervous system function. However, our findings are preliminary, due to the limited number of proteins indentified in the MS analysis. Future investigations of larger numbers of proteins that are differentially expressed in the hippocampus are required to confirm our findings and provide greater insight into the stress-induced changes in the proteomic profile of the hippocampus.

\section{Abbreviations}




\begin{tabular}{|ll|}
\hline 2DE & two-dimensional electrophoresis \\
\hline SPTAN1 & spectrin alpha chain, non-erythrocyte 1 \\
\hline MYH4, & myosin-4 \\
\hline HSPA8 & heat shock cognate 71 kDa protein \\
\hline HS90A & heat shock protein HSP 90-alpha \\
\hline DYN1 & dynamin-1 \\
\hline DLDH & dihydrolipoyl dehydrogenase mitochondrial \\
\hline ARP3 & actin-related protein 3 \\
\hline GLNA & glutamine synthetase \\
\hline SAHH & adenosyl homocysteinase \\
\hline HBB1 & hemoglobin subunit beta-1 \\
\hline ACLY & ATP-citrate synthase \\
\hline TBB2A & tubulin beta-2A chain \\
\hline GBB1 & guanine nucleotide-binding protein G(I)/G(S)/G(T) subunit beta-1 \\
\hline SD rats & Sprague-Dawley rats \\
\hline IEF & Isoelectric focusing \\
\hline GO & Gene ontology \\
\hline qRT-PCR & quantitative real-time PCR \\
\hline
\end{tabular}

\section{Declarations}

\section{Author Contributions}

Lin Han, Xiaofan Xiong, Meiyang Fan and Lingyu Zhang raised animals, built animal models and performed the Morris water maze test experiments of rats together. Lin Han performed the Western blotting validation of proteins and was a major contributor in writing the manuscript. Liying Liu analyzed the result of the Morris water maze test experiments. Chen Guo and Shanfeng Gao conducted the sample preparation. Lingyu Zhao analyzed the result of Western blotting validation of proteins. Xiaofei Wang was responsible for the GO analysis of differentially expressed proteins. Xuan Xiao analyzed the result of protein identification by MALDI-TOF-MS. Chen Huang and Juan Yang guided the whole experiment design and promotion as well as the article writing. All authors read and approved the final manuscript.

\section{Funding}


This work was supported by the National Natural Science Foundation of China (Grant number: 81671445 and 81200845$)$.

\section{Acknowledgments}

This work was supported by the grant from the National Natural Science Foundation of China (81671445 and 81200845 ) to Juan Yang. We thank International Science Editing for editing this manuscript (http://www.internationalscienceediting.com).

\section{Conflicts of Interest}

The authors declare no conflict of interest.

\section{References}

1. van Bodegom, M., J.R. Homberg, and M. Henckens, Modulation of the Hypothalamic-PituitaryAdrenal Axis by Early Life Stress Exposure. Front Cell Neurosci, 2017. 11: p. 87.

2. Ruiz, R., et al., Early life stress accelerates age-induced effects on neurogenesis, depression, and metabolic risk. Psychoneuroendocrinology, 2018. 96: p. 203-211.

3. Gomes, F.V. and A.A. Grace, Prefrontal Cortex Dysfunction Increases Susceptibility to Schizophrenia-Like Changes Induced by Adolescent Stress Exposure. Schizophr Bull, 2017. 43(3): p. 592600 .

4. McEwen, B.S., J.M. Weiss, and L.S. Schwartz, Selective retention of corticosterone by limbic structures in rat brain. Nature, 1968. 220(5170): p. 911-2.

5. Bayer, S.A., Development of the Hippocampal Region in the Rat .2. Morphogenesis during Embryonic and Early Postnatal Life. Journal of Comparative Neurology, 1980. 190(1): p. 115-134.

6. Gall, C. and G. Lynch, Rapid axon sprouting in the neonatal rat hippocampus. Brain Res, 1978. 153(2): p. 357-62.

7. Lin, L.Y., et al., Early-life stress leads to impaired spatial learning and memory in middle-aged ApoE4-TR mice. Mol Neurodegener, 2016. 11(1): p. 51.

8. Seehagen, S., et al., Stress impairs cognitive flexibility in infants. Proc Natl Acad Sci U S A, 2015. 112(41): p. 12882-6.

9. Rice, C.J., et al., A novel mouse model for acute and long-lasting consequences of early life stress. Endocrinology, 2008. 149(10): p. 4892-900. 
10. Brunson, K.L., et al., Stress and the developing hippocampus: a double-edged sword? Mol Neurobiol, 2003. 27(2): p. 121-36.

11. Inoue, N., Stress and atherosclerotic cardiovascular disease. J Atheroscler Thromb, 2014. 21(5): p. 391-401.

12. Iwata, M., K.T. Ota, and R.S. Duman, The inflammasome: pathways linking psychological stress, depression, and systemic illnesses. Brain Behav Immun, 2013. 31: p. 105-14.

13. Park, G., et al., Melatonin inhibits neuronal dysfunction-associated with neuroinflammation by atopic psychological stress in NC/Nga atopic-like mouse models. J Pineal Res, 2017. 63(2).

14. Lukowiak, K., et al., Ecologically relevant stressors modify long-term memory formation in a model system. Behav Brain Res, 2010. 214(1): p. 18-24.

15. de Quervain, D.J., B. Roozendaal, and J.L. McGaugh, Stress and glucocorticoids impair retrieval of long-term spatial memory. Nature, 1998. 394(6695): p. 787-90.

16. Uhelski, M.L. and P.N. Fuchs, Maternal separation stress leads to enhanced emotional responses to noxious stimuli in adult rats. Behav Brain Res, 2010. 212(2): p. 208-12.

17. Pesonen, A.K., et al., Childhood separation experience predicts HPA axis hormonal responses in late adulthood: A natural experiment of World War II. Psychoneuroendocrinology, 2010. 35(5): p. 758-767.

18. Zhu, X., et al., [Effect of maternal deprivation on emotion and expression of dopamine transporter in adult rats]. Zhong Nan Da Xue Xue Bao Yi Xue Ban, 2010. 35(1): p. 32-7.

19. Wang, Z., et al., [Effect of chronic stress on PKA and P-CREB expression in hippocampus of rats and the antagonism of antidepressors]. Zhong Nan Da Xue Xue Bao Yi Xue Ban, 2006. 31(5): p. 767-71.

20. Awerman, J.L. and L.M. Romero, Chronic psychological stress alters body weight and blood chemistry in European starlings (Sturnus vulgaris). Comp Biochem Physiol A Mol Integr Physiol, 2010. 156(1): p. 136-42.

21. Conboy, L. and C. Sandi, Stress at Learning Facilitates Memory Formation by Regulating AMPA Receptor Trafficking Through a Glucocorticoid Action. Neuropsychopharmacology, 2010. 35(3): p. 674685 .

22. Bordner, K.A., et al., Functional genomic and proteomic analysis reveals disruption of myelinrelated genes and translation in a mouse model of early life neglect. Front Psychiatry, 2011. 2: p. 18.

23. Yang, J., et al., A terrified-sound stress induced proteomic changes in adult male rat hippocampus. Physiol Behav, 2014. 128: p. 32-8. 
24. Hueston, C.M., J.F. Cryan, and Y.M. Nolan, Stress and adolescent hippocampal neurogenesis: diet and exercise as cognitive modulators. Translational Psychiatry, 2017. 7.

25. Ibi, D., et al., Social isolation rearing-induced impairment of the hippocampal neurogenesis is associated with deficits in spatial memory and emotion-related behaviors in juvenile mice. J Neurochem, 2008. 105(3): p. 921-32.

26. Isgor, C., et al., Delayed effects of chronic variable stress during peripubertal-juvenile period on hippocampal morphology and on cognitive and stress axis functions in rats. Hippocampus, 2004. 14(5): p. 636-48.

27. Kim, E.J., B. Pellman, and J.J. Kim, Stress effects on the hippocampus: a critical review. Learn Mem, 2015. 22(9): p. 411-6.

28. Fountoulakis, M., et al., The rat brain hippocampus proteome. J Chromatogr B Analyt Technol Biomed Life Sci, 2005. 819(1): p. 115-29.

29. Huang, C.Y., et al., alphall Spectrin Forms a Periodic Cytoskeleton at the Axon Initial Segment and Is Required for Nervous System Function. J Neurosci, 2017. 37(47): p. 11311-11322.

30. Stankewich, M.C., et al., Cell organization, growth, and neural and cardiac development require alphall-spectrin. J Cell Sci, 2011. 124(Pt 23): p. 3956-66.

31. Wang, Y., et al., Critical roles of alphall spectrin in brain development and epileptic encephalopathy. J Clin Invest, 2018. 128(2): p. 760-773.

32. Syrbe, S., et al., Delineating SPTAN1 associated phenotypes: from isolated epilepsy to encephalopathy with progressive brain atrophy. Brain, 2017. 140(9): p. 2322-2336.

33. Yoshihara, T., et al., Age-related changes in histone modification in rat gastrocnemius muscle. Exp Gerontol, 2019. 125: p. 110658.

34. Stricher, F., et al., HSPA8/HSC70 chaperone protein: structure, function, and chemical targeting. Autophagy, 2013. 9(12): p. 1937-54.

35. Stetler, R.A., et al., Heat shock proteins: cellular and molecular mechanisms in the central nervous system. Prog Neurobiol, 2010. 92(2): p. 184-211.

36. Ahn, S.G., et al., Heat-shock cognate 70 is required for the activation of heat-shock factor 1 in mammalian cells. Biochem J, 2005. 392(Pt 1): p. 145-52.

37. Fukudo, S., et al., Psychophysiological stress induces heat shock cognate protein 70 messenger RNA in the hippocampus of rats. Neuroscience, 1999. 91(4): p. 1205-8. 
38. van Bodegraven, E.J., et al., Importance of GFAP isoform-specific analyses in astrocytoma. Glia, 2019. 67(8): p. 1417-1433.

39. Dallerac, G. and N. Rouach, Astrocytes as new targets to improve cognitive functions. Progress in Neurobiology, 2016. 144: p. 48-67.

40. Hagemann, T.L., J.X. Connor, and A. Messing, Alexander disease-associated glial fibrillary acidic protein mutations in mice induce Rosenthal fiber formation and a white matter stress response. $\mathrm{J}$ Neurosci, 2006. 26(43): p. 11162-73.

41. Araya-Callis, C., et al., Chronic psychosocial stress and citalopram modulate the expression of the glial proteins GFAP and NDRG2 in the hippocampus. Psychopharmacology (Berl), 2012. 224(1): p. 20922.

\section{Figures}

A

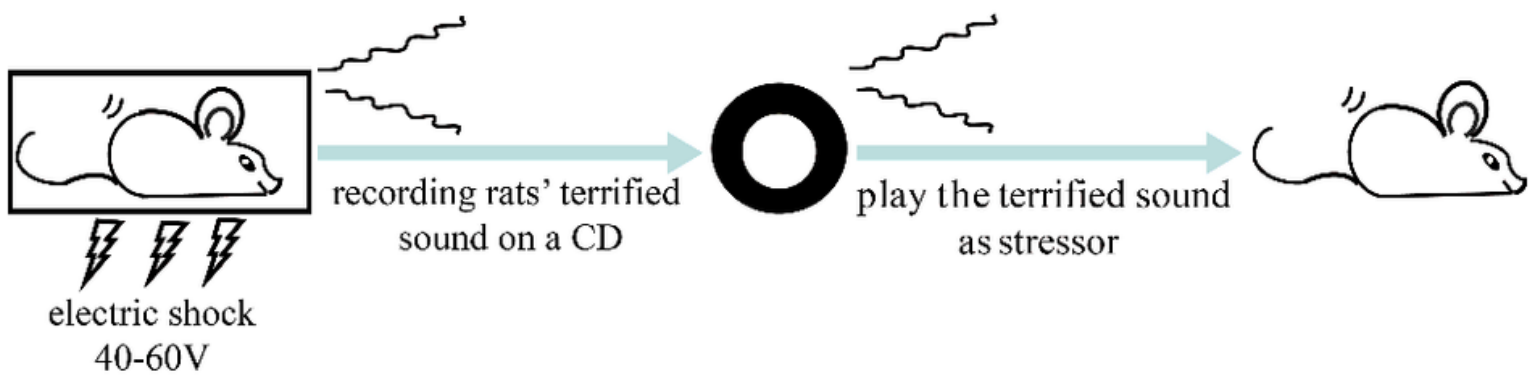

B

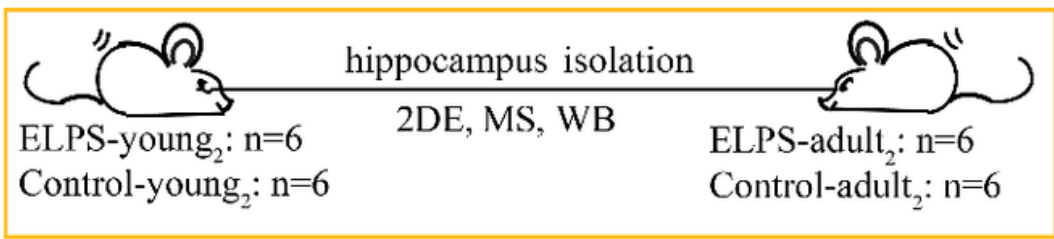

ELPS

a terrified sound stress in early-life

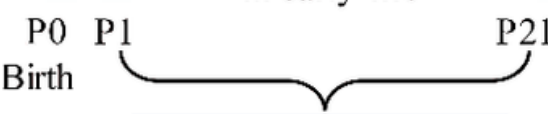

ELPS-young: $n=20$ Control-young: $n=20$ ELPS-adult: $\mathrm{n}=20$ Control-adult: $\mathrm{n}=20$

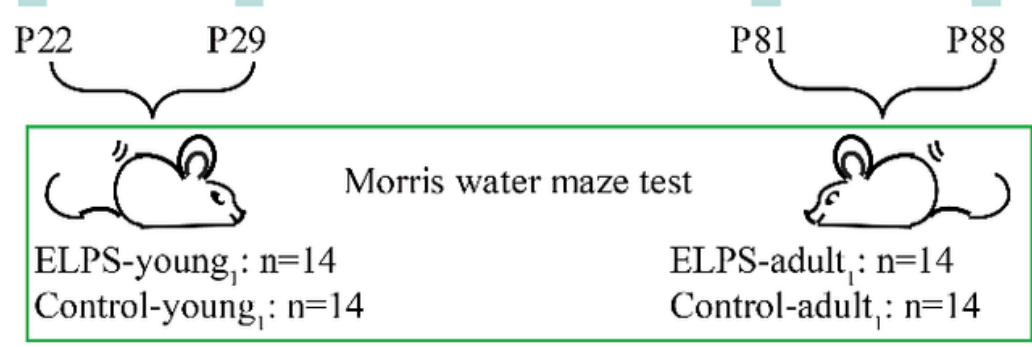

Figure 1 
Early-life psychological stress (ELPS) animal model and experimental procedures. (A) Rats were exposed to a 40-60V electric foot shock, and their terrified sound in response to the electric shock were simultaneously recorded in a professional recording room. We exposed other rats to the recorded terrified vocalization to induce psychological stress. (B) With their mothers, pups on postnatal day 1 (P1) were exposed to the terrified sound to induce early-life psychological stress (ELPS). At P22, after ELPS exposure, Control-young group $(n=14)$ and ELPS-young group $(n=14)$ were tested for learning and memory ability by the Morris water maze test. To explore whether ELPS mediated spatial learning and memory ability in adult rats, Control-adult group $(n=14)$ and ELPS-adult group $(n=14)$ were raised without additional treatment until 80 days and then underwent a Morris water maze test. The hippocampal tissues of rats $(n=6)$ per group were prepared for 2DE, MS and Western blotting. 
A
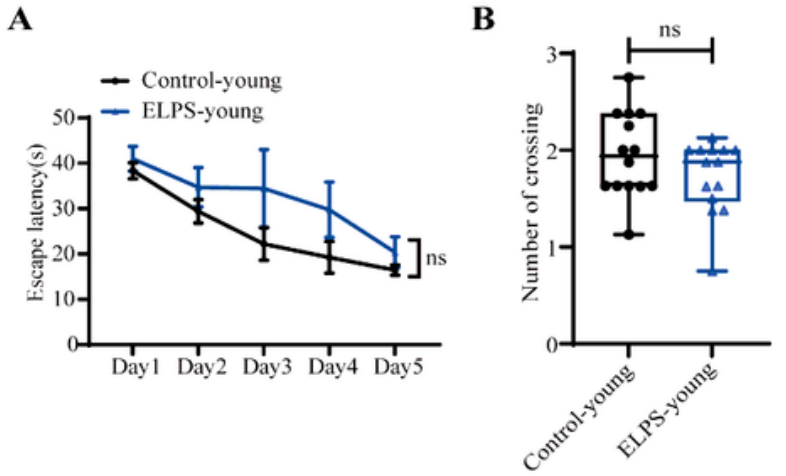

C

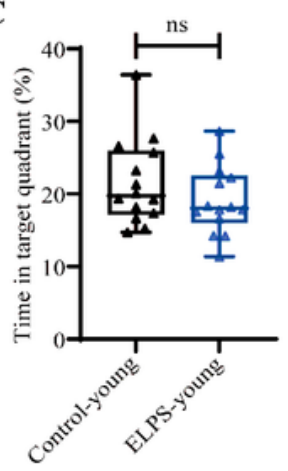

D

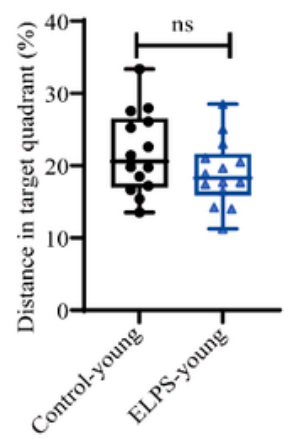

E

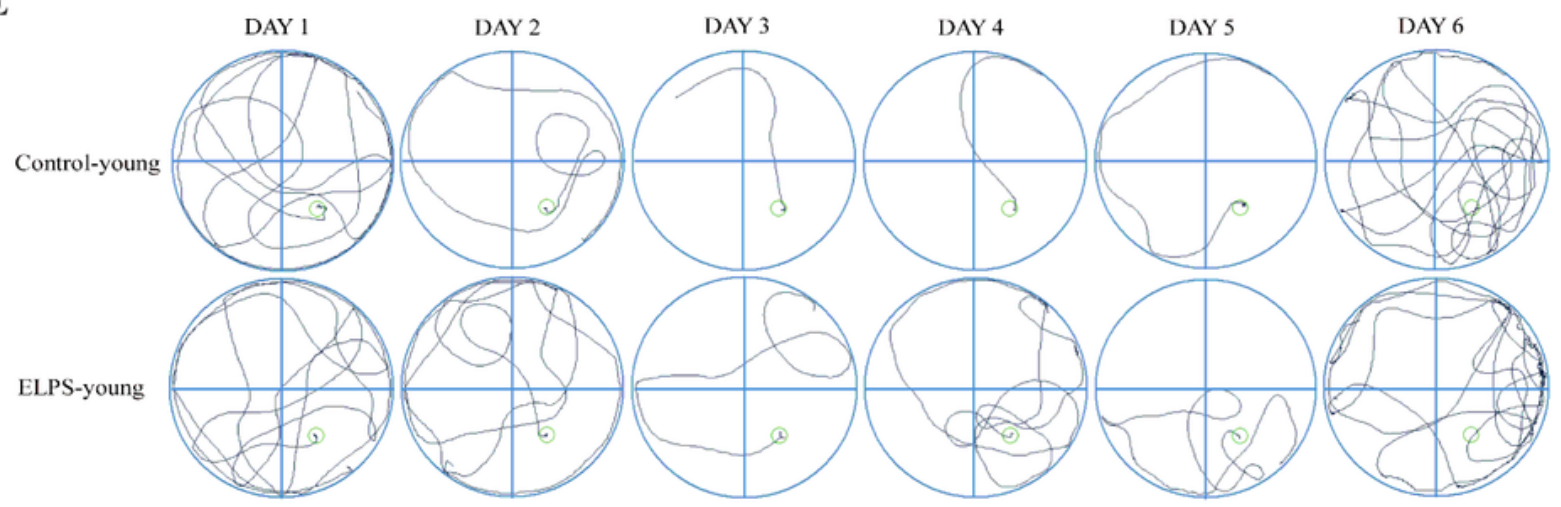

F

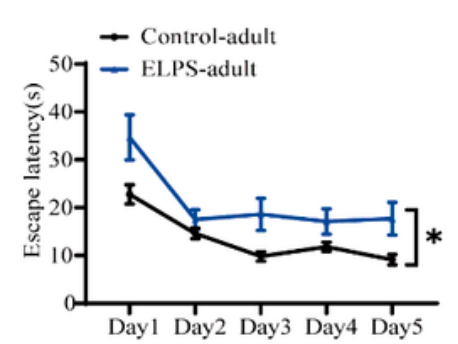

G

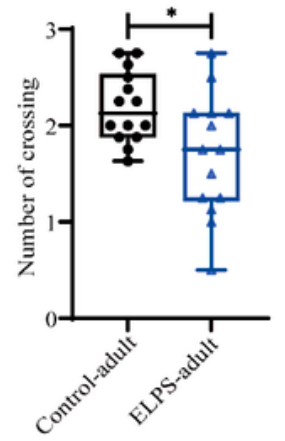

H

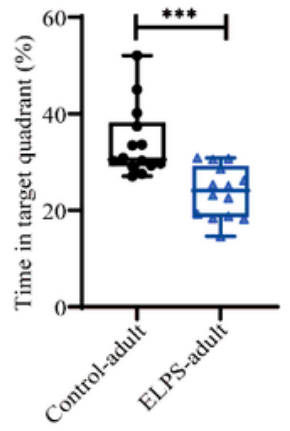

I

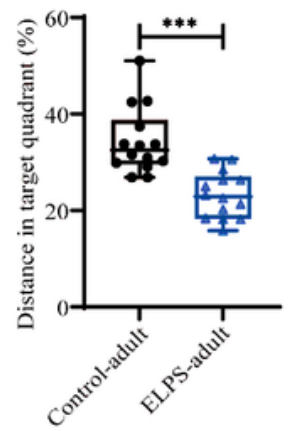

J

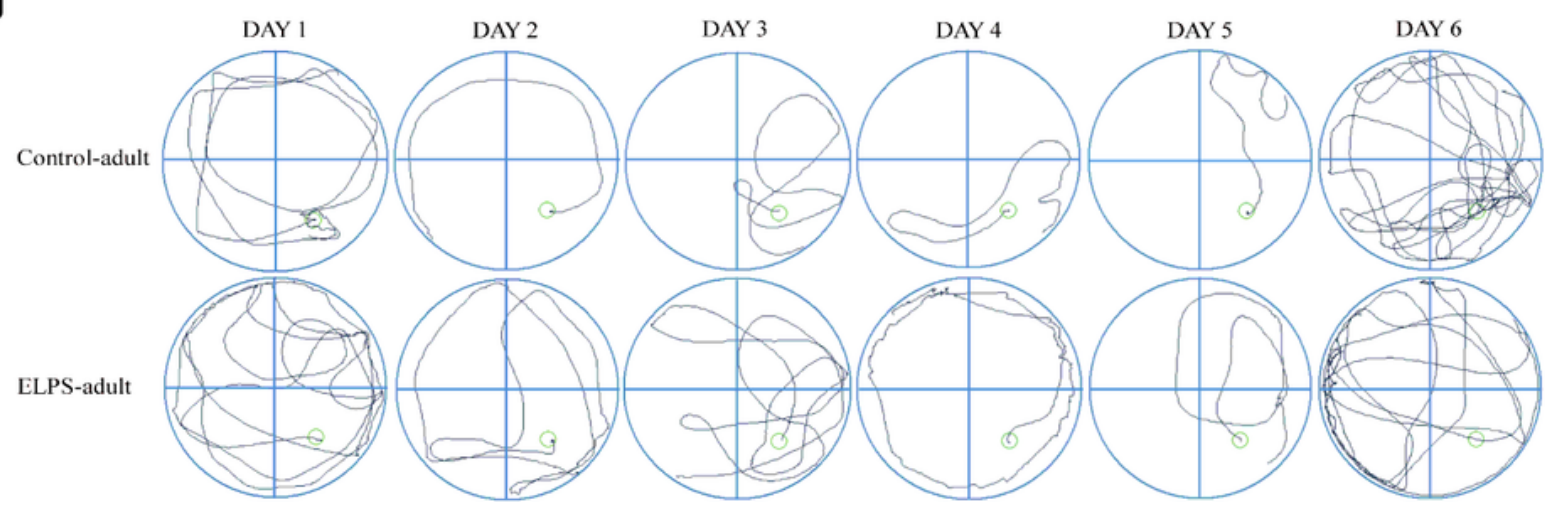

Figure 2

Effects of the ELPS on spatial learning and memory. (A-D) The ELPS-young group required more time to find escape platform; had fewer number of times crossing the platform position; spent less time and had less distance in the target quadrant, but there was no significant difference between the two groups. (F-I) The ELPS-adult group required more time to find escape platform; had less times crossing the platform position; spent less time and had less distance in the target quadrant, and there was significant 
difference between the two groups. $(E, J)$ Representative swimming tracks of all groups in the Morris Water Maze test for days 1-5 of training and day 6 of the probe trial. $N=14$ per group. $\left({ }^{*} P<0.05,{ }^{\star} P<0.01\right.$, $\star \star * P<0.001$; NS: not significant).

A

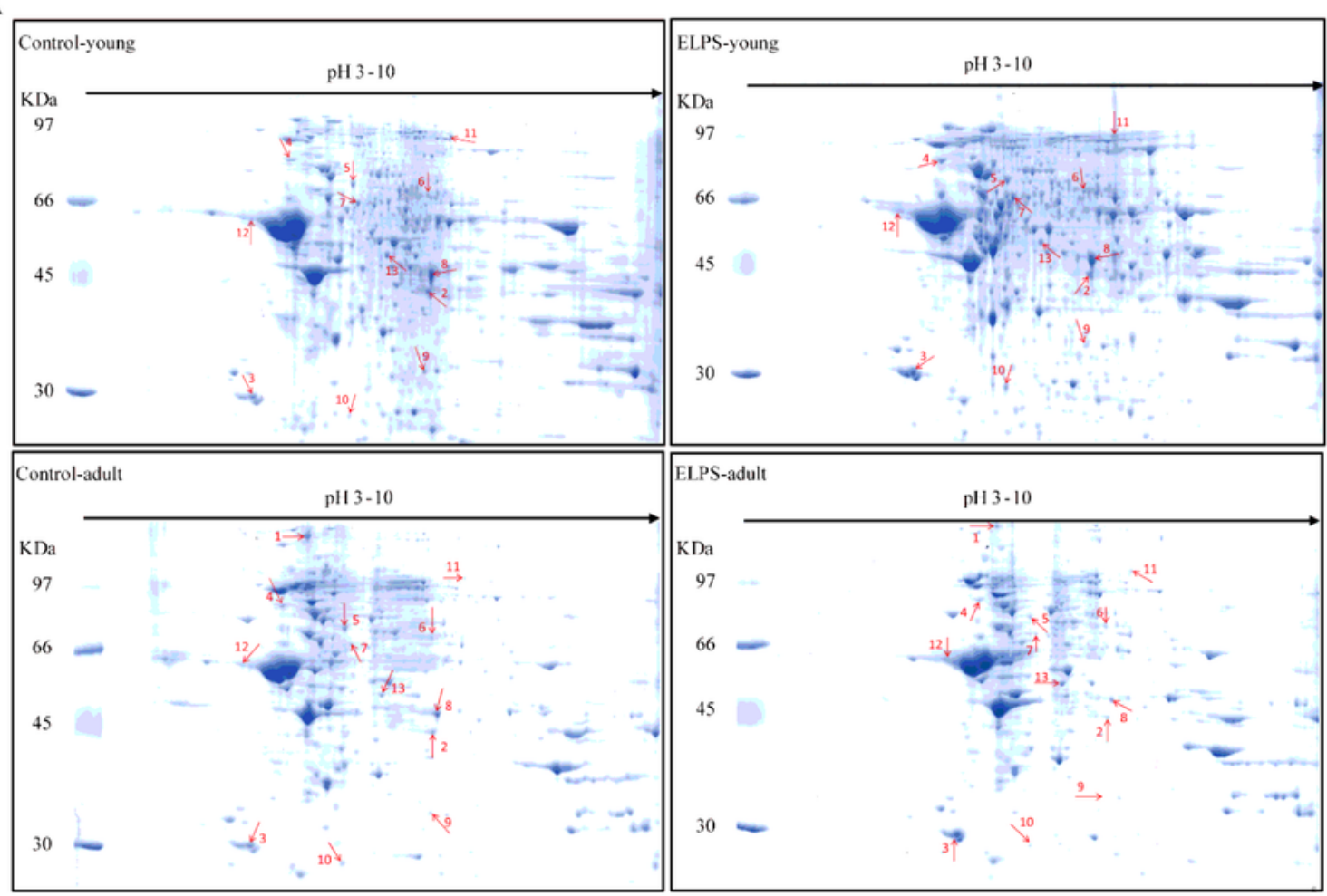

B

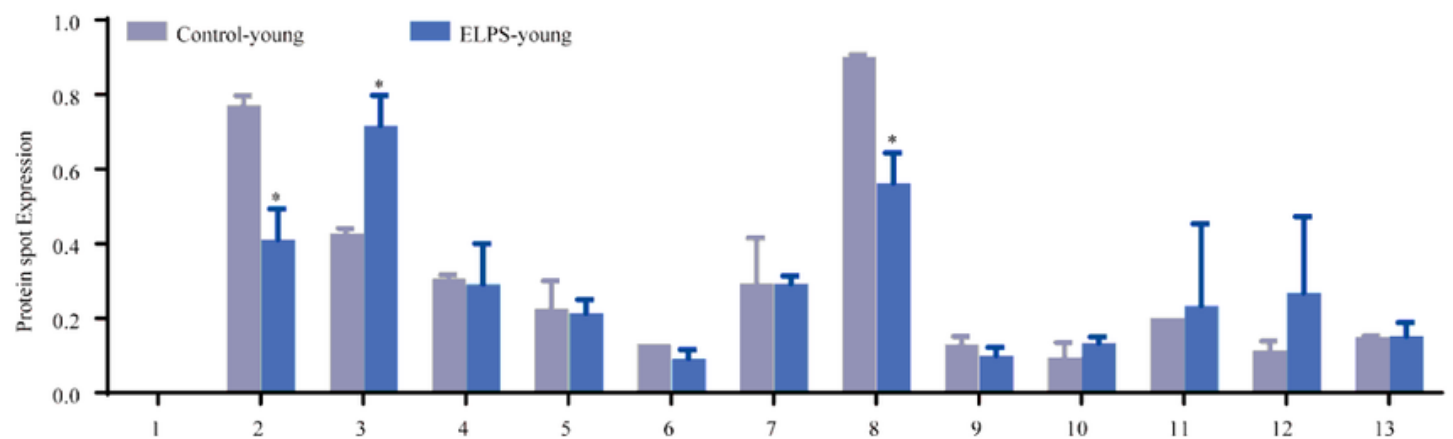

C

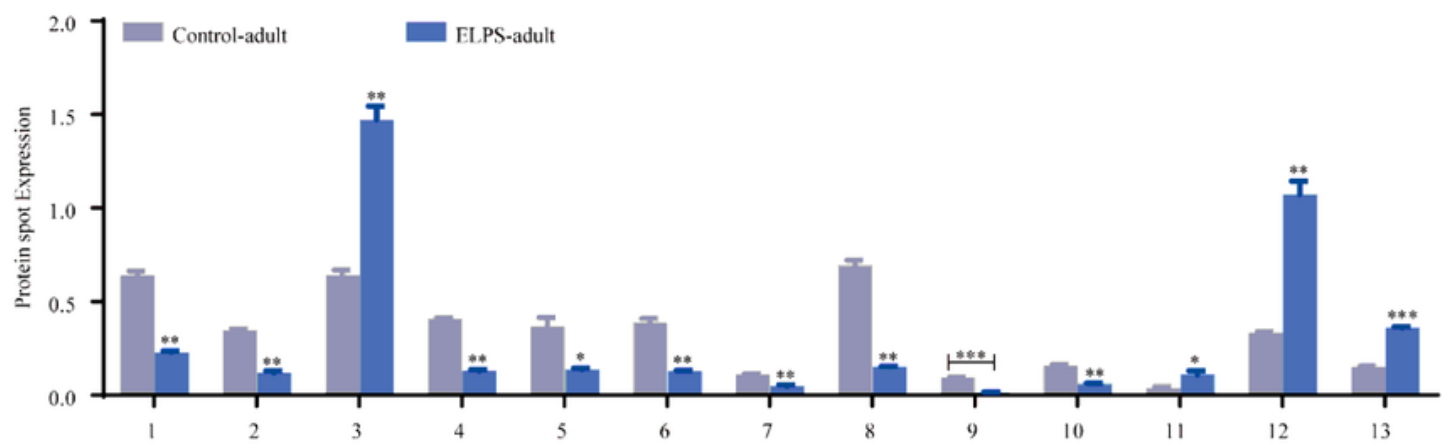

Figure 3

Different protein spots expression in 2DE gels. (A) Representative 2DE map of rat hippocampus proteome from the Control-young group, ELPS-young group, Control-adult group and ELPS-adult group. The 
expression quantity of 13 spots corresponding to the most significant differentially expressed proteins between the Control-young group and ELPS-young group (B); Control-adult group and ELPS-adult group (C). The figures used the independent Student's t-test of statistical methods. ${ }^{*} P<0.05,{ }^{\star *} P<0.01$, $* * * \mathrm{P}<0.001$.

A

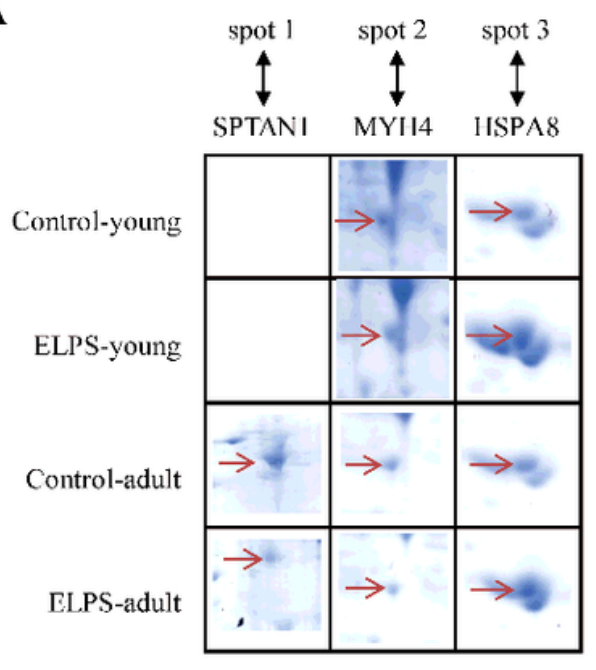

B

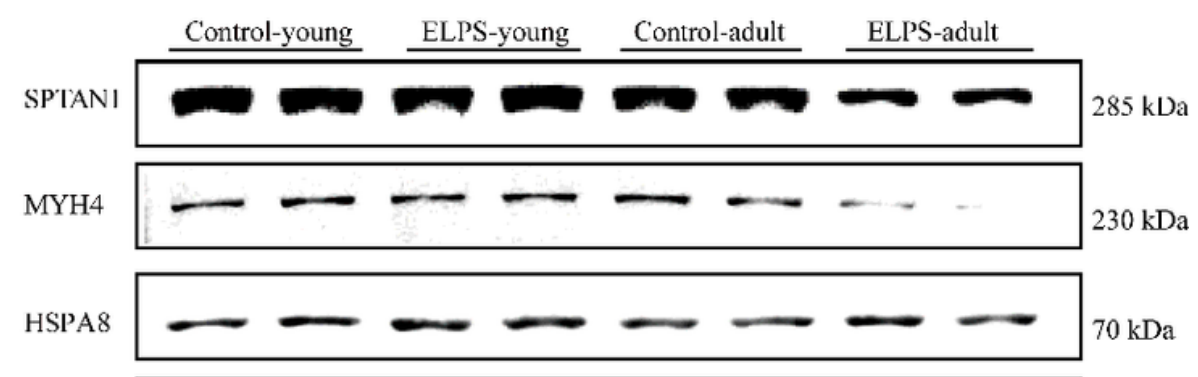

GiFAP

$\beta$-actin $43 \mathrm{kDa}$

\section{Figure 4}

Identification and validation of differentially expressed proteins. (A) Differentially concentrated spots (1, 2,3 ) identified as SPTAN1, MYH4, HSPA8 by MALDI-TOF-MS are marked with red arrows in the Controlyoung group, ELPS-young group, Control-adult group and ELPS-adult group. (B) Western blotting analysis of SPTAN1, MYH4, HSPA8 and GFAP in the hippocampus of Control-young group, ELPS-young group, Control-adult group and ELPS-adult group. 
$\mathbf{A}$

Biological Process

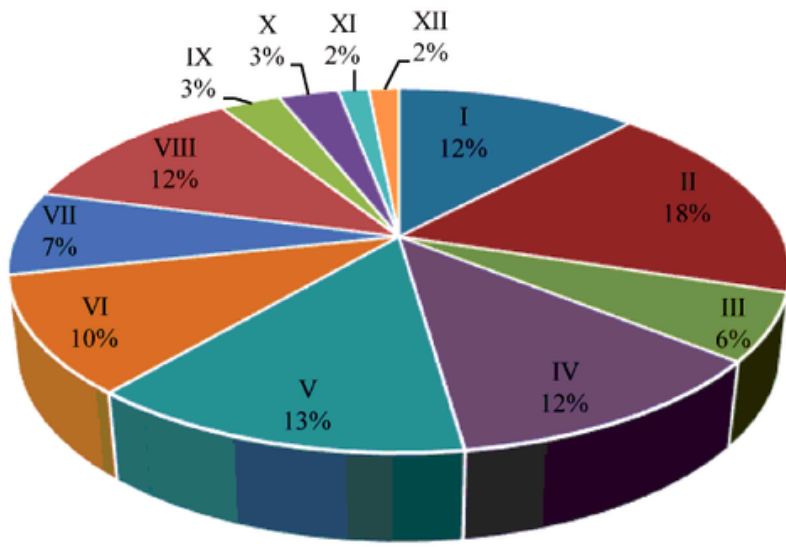

I cellular component organization or biogenesis

GO:0071840

II cellular process

GO:0009987

III localization

GO:0051179

IV biological regulation

GO:0065007

$\mathrm{V}$ response to stimulus

GO:0050896

VI developmental process

GO:0032502

VII multicellular organismal process

GO:0032501

VIII metabolic process

GO:0008152

IX reproduction

$\mathrm{X}$ cell population proliferation

GO:0000003

GO:0008283

XI rhythmic process

GO:0048511

XII behavior

GO:0007610

B

Molecular Function

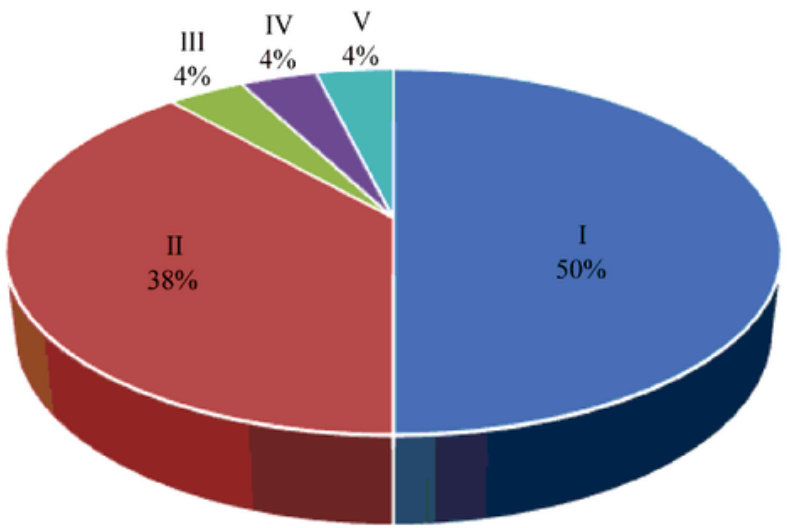

I binding

GO:0005488

II catalytic activity

GO:0003824

III protein folding chaperone

GO:0044183

IV transporter activity

GO:0005215

V structural molecule activity

GO:0005198

C

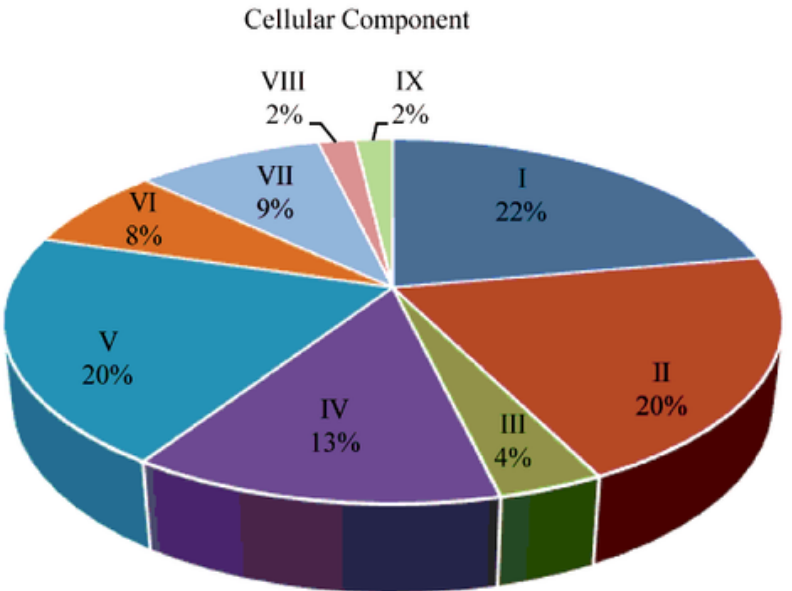

I cell part

GO:0044464

II organelle

GO:0043226

III extracellular region

GO:0005576

IV membrane

GO:0016020

V protein-containing complex

GO:0032991

VI supramolecular complex

GO:0099080

VII synapse

GO:0045202

VIII membrane -enclosed lumen

GO:0031974

IX cell junction

GO:0030054

\section{Figure 5}

Classification of the identified proteins. Proteins were classified using UnitProtKB and GO database according to their (A) biological processes, (B) molecular functions and (C) cellular components. 